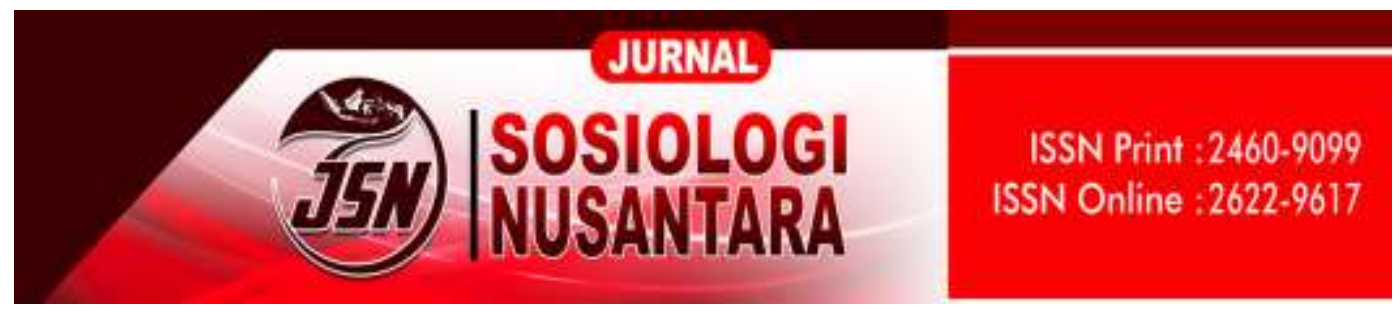

\title{
SRAWUNG: IMPLEMENTASI BUDAYA PERUSAHAAN \\ DALAM PENGELOLAAN KEDAI KOPI \\ DI MAGISTRA COFFEE YOGYAKARTA
}

\section{SRAWUNG: IMPLEMENTATION OF CORPORATE CULTURE IN MANAGING COFFEE SHOPS IN MAGISTRA COFFEE YOGYAKARTA}

\section{Bayundaru Hadiprabuono}

bayundaru@gmail.com

\section{Program Studi Magister Antropologi Fakultas Ilmu Sosial dan Politik, Universitas Indonesia}

\begin{abstract}
Abstrak
Penelitian ini berfokus pada studi yang berkaitan dengan kopi dalam konteks budaya pada pengelolaan kedai kopi dengan memasukkan konsep budaya perusahaan dan identitas. Kajian yang dilakukan bertujuan untuk memperjelas signifikansi relasi antara penjual dan pembeli dalam melihat kebertahanan kedai kopi berskala kecil di tengah persaingan bisnis yang ketat. Data tulisan hasil riset ini diperoleh melalui wawancara mendalam mengenai sejarah hidup individuindividu yang terkait dengan pengelolaan organisasi perusahaan kedai kopi. Hasil penelitian ini menyatakan bahwa kedekatan hubungan secara emosional antara pihak penjual dan pembeli terbangun karena adanya budaya perusahaan (srawung) yang berorientasi lebih kepada pelayanan daripada produk kopinya sendiri. Hubungan tersebut melahirkan identitas dan reputasi yang berguna bagi kedai kopi untuk merawat para pelanggannya. Budaya srawung juga digunakan secara berkelanjutan sebagai dasar dalam pengelolaan identitas dan reputasi yang didapatkannya. Fokus pada merawat pelanggan sehingga menciptakan pelangganpelanggan loyal pada akhirnya mengarahkan pada kepastian penjualan. Hal tersebut dinilai relevan daripada berfokus pada peningkatan penjualan di saat banyak kedai kopi kecil yang berumur pendek karena semakin banyak kompetitor yang bermunculan.
\end{abstract}

Kata Kunci : Barista, Budaya Perusahaan, Identitas, Kedai Kopi, Reputasi 


\begin{abstract}
This research focuses on studies related to coffee in the cultural context of coffee shop management by incorporating the concept of corporate culture and identity. The study conducted aims to clarify the significance of the relationship between sellers and buyers in seeing the sustainability of small-scale coffee shops in the midst of intense business competition. The written data of the research results were obtained through in-depth interviews regarding the life histories of individuals associated with the management of coffee shop company organizations. The results of this study indicate that the closeness of the emotional relationship between the seller and the buyer is built because of the company culture (srawung) which is more service oriented than the coffee product itself. This relationship creates an identity and reputation that is useful for the coffee shop to care for its customers. The culture of srawung is also used sustainably as a basis for managing the identity and reputation it earns. Focus on caring for customers so as to create loyal customers ultimately leads to certainty of sales. This is considered relevant rather than focusing on increasing sales at a time when many small coffee shops are shortlived as more competitors emerge.
\end{abstract}

Keywords : Barista, Coffee Shop, Corporate Culture, Identity, Reputation

\title{
PENDAHULUAN
}

Dewasa ini kedai kopi begitu menjamur dikarenakan menjadi pilihan banyak kalangan sebagai tempat untuk berkumpul dan mengerjakan berbagai pekerjaan, sehingga melahirkan apa yang disebut sebagai coffee culture. Istilah tersebut menunjuk pada kebiasaan khusus dan interaksi sosial yang berlangsung di sekitar kopi dan kedai kopi. Istilah ini mulai populer sejak Stamberg (2002) dan Tucker (2011) yang dalam penelitiannya memperlihatkan beberapa contohnya, yaitu mengundang seseorang keluar untuk minum kopi, membeli kopi sebelum bekerja di pagi hari, menghabiskan waktu luang serta bekerja di kedai kopi.

Terbentuknya coffee culture dalam penelitian-penelitian terdahulu (Berg 2008; de Koning 2006; Arjomand 2004; Thompson dan Arsel 2004; Reitz 2007; Komecoglu 2005; Haine 1996; Ellis 2011; Cowan 2008; Pendergrast 2010; Biderman 2013; Waxman 2006) menggunakan konsep food culture sebagai dasar analisis yang dielaborasi dengan isu mengenai perilaku konsumen dengan metodologi penelitian sejarah untuk menjelaskan variasi coffee culture yang 
terbentuk. Pada umumnya mereka berupaya memahami makna sosial dari penggunaan kedai kopi dalam kehidupan sehari-hari konsumen.

Berbagai penelitian di atas, sejauh pemahaman penulis melihat kedai kopi hanya dari sudut pandang pelanggan, menjadi ruang ketiga setelah rumah dan kantor sehingga ditempatkan oleh para peneliti sebagai "lokasi penting" untuk melihat pengalaman sosial. Terdapat kelangkaan studi etnografi yang memfokuskan secara khusus pada sudut pandang pelaku kedai kopi itu sendiri sebagai pihak yang mengakomodir lahirnya coffee culture. Sejauh penelusuran penulis, ada beberapa penelitian etnografi yang pernah dilakukan, antara lain Laurier (2001) yang melihat keterkaitan antara pemilik kedai kopi dengan keadaan lingkungan kedai kopinya. Dia melihat bahwa pengaturan ruang kedai kopi yang sengaja dilakukan pemiliknya mampu menciptakan kondisi lingkungan dan interaksi yang khas antara para konsumen dan para karyawan. Selanjutnya, penelitian Milligan (1998) tentang keterikatan emosional yang dimiliki karyawan dengan pengaturan fisik (tata ruang dan desain interior) kedai kopinya, namun dalam studinya itu kopi masih bersifat epifenomenal. Penelitian dengan sudut pandang barista, juga dilakukan oleh Manning (2008) yang melihat beberapa model percakapan yang dibangun di ruang publik oleh karyawan Starbucks dengan konsumennya untuk melihat tingkat kepuasan pelanggan terhadap pelayanan yang diberikan.

Kopi memang komoditas yang penting tidak hanya untuk ekonomi negara, tetapi juga di tingkat mikro sosial sebagai sumber daya sosialisasi antarindividu. Bagi subkultur pecinta kopi tertentu (gelombang ketiga), kopi itu sendiri adalah topik yang menjadi fokus pengorganisasian. Penelitian soal kedai kopi yang memfokuskan kopi sebagai fenomena utamanya terdapat pada penelitian Manzo (2010). Dia berfokus pada pengalaman konsumsi kopi, kehidupan bersama para pencinta kopi dan pemilik kedai kopi yang melayani mereka. Kedai kopinya sendiri tidak diperlakukan sebagai topik maupun sumber daya untuk analisis empiris. Fokusnya adalah pada narasi para penikmat kopi dan refleksi mereka tentang perkenalan dan perolehan "rasa" saat meminum kopi serta konsekuensi dari partisipasi mereka dalam subkultur kopinya. 
Manzo (2015) melanjutkan penelitiannya dengan memprioritaskan pada perilaku barista. Dia berpendapat bahwa di dalam kedai kopi subkultur gelombang ketiga, tatap muka dan interaksi yang intens antara karyawan dan pelanggan tumbuh subur di tengah hilangnya banyak tempat pertemuan publik tradisional. Barista menggunakan fitur khas subkultur ini seperti mendemonstrasikan keahliannya saat mempersiapkan minuman kopi dengan berbagai narasi seputar kopi untuk membangun interaksi dengan pelanggan.

Kedai kopi dengan subkultur tersebut juga terdapat di Yogya. Kedai kopi itu menjadi wadah yang populer untuk memperkenalkan dan menawarkan berbagai varian menu kopi. Para pemilik kedai kopi menjadikan ketersediaan berbagai pilihan kopi di kedainya sebagai daya tarik. Salah satunya, kopi-kopi dari berbagai wilayah di Indonesia yang dapat dilihat dari dicantumkannya indikasi geografis pada label wadah kopi.

Penelitian ini menambahkan penelitian yang ada dengan memindahkan sudut pandang pada pihak penjual dan fokus melihat pada kapasitas dan pengelolaan kedai kopinya. Pada industri kedai kopi di Yogya, penulis melihat ada kondisi yang berbeda. Di beberapa kedai kopi, khususnya yang memiliki daya tampung kecil berkisar maksimal dua puluh orang, para pemiliknya ikut terjung langsung dalam operasional sehari-hari dan aktif membuatkan kopi pesanan konsumen secara bergantian dengan baristanya. Namun, sejauh penelusuran penulis tidak banyak dari kedai-kedai kopi berukuran kecil ini yang mampu bertahan menghadapi kompetitor yang semakin banyak hingga berumur panjang (berusia di atas lima tahun). Berangkat dari temuan empiris tersebut, belakangan masuknya para investor juga mengarah pada kedai-kedai kopi kecil. Hal ini memperlihatkan para investor pun tidak berani berspekulasi dengan membuka kedai kopi berukuran besar. Mereka lebih memilih mengelola konsumen dengan jumlah sedikit demi menjaga keberlangsungan bisnisnya, meskipun mereka tetap mendelegasikan wewenang pengelolaan kedai kopi kepada orang-orang yang sudah berpengalaman, dan memiliki peta perkembangan bisnis kopi yang mumpuni.

Penelitian ini membahas persoalan kemampuan bertahannya kedai kopi berukuran kecil dengan pemiliknya secara konsisten ikut melayani pembeli tanpa 
campur tangan investor. Fokus ini menjadi menarik karena meskipun jumlah konsumen yang dibutuhkan kecil, ternyata tidak banyak yang berumur panjang. Salah satu kedai kopi kecil yang mampu bertahan hingga tahun kelima adalah Magistra Coffee. Kedai kopi ini menjadi kasus yang menarik karena selain kedai kopinya kecil dan berada di dalam kantin kampus dengan segmen pasar yang telah tersedia, mereka juga menghadapi persoalan dalam menarik minat konsumen. Tidak serta merta konsumen yang datang ke kantin membeli produk mereka, begitu juga dengan terlibat langsungnya sosok yang mumpuni di bidang kopi (pemilik) tidak secara otomatis mendatangkan konsumen. Pada akhirnya, persoalan kesuksesan dan keberlanjutan kedai kopi berukuran kecil di tengah persaingan yang semakin ketat itu, terlibatnya sosok yang berpengalaman serta segmen pasar jelas perlu dilihat lebih jauh dalam pengelolaannya.

Dalam antropologi, kebiasaan mengonsumsi makanan atau minuman dilihat sebagai suatu aktivitas kuliner kompleks yang pada proses produksi, persiapan dan konsumsi berkaitan dengan persoalan selera yang dilatarbelakangi oleh banyak hal seperti kepercayaan, pantangan, cerita rakyat dan persepsi mistis (Foster and Anderson, 1986: 313). Telfer (2012:2) juga berpendapat bahwa aktivitas makan manusia tidak saja demi mempertahankan hidup, tetapi juga mencerminkan kebebasan dalam memilih (terkait kenikmatan). Lebih lanjut, Montanari (2004:2021) mengatakan bahwa makanan/minuman telah beralih dari kebutuhan biologis ke pengalaman estetis, yaitu pada persoalan memenuhi selera dan memuaskan kesenangan.

\section{METODE PENELITIAN}

Penelitian ini menggunakan pendekatan etnografi karena memiliki kemampuan untuk menjawab pertanyaan penelitian dengan cara membawa peneliti lebih dekat dengan subjek penelitian, apa yang sedang dipelajari informan dan memungkinkan peneliti untuk menangkap proses sosial yang mereka alami (Denzin dan Lincoln, 1994). Dalam desain etnografi, subjek penelitian di lapangan adalah orang yang berinteraksi, paling mengenal, dan memiliki reputasi atas setting serta sejarah dari topik yang sedang diteliti (Weber, 2001).

Melalui pendekatan etnografi, artinya penulis melakukan pengamatan 
terlibat (participant observation) dengan bekerja sebagai barista selama tiga bulan agar dapat secara intensif mengamati proses dan interaksi yang berlangsung selama operasionalisasi kedai kopi. Untuk mendapatkan data tentang cara pengelolaan kedai kopi yang melibatkan individu-individu tertentu, penulis menerapkan metode life histories. Fetterman (1989:61) mengatakan,

“Life history is key actor's detailed autobiographical description. In some instances the life history may not be verifiable or even factually accurate. In these cases, the life history is still invaluable because the record captures an individual's perception of the past, providing a unique look at how the key actor thinks and how personal and cultural values shape his or her perception of the past."

Walaupun sejarah kehidupan sulit untuk diverifikasi, life history tetap merupakan suatu teknik pengumpulan data yang berguna untuk mendapatkan deskripsi kehidupan seseorang secara rinci. Kottak (2011: 55) juga menjelaskan bahwa metode ini dilakukan dengan menggali ingatan dan kenangan hidup seseorang untuk melihat pengalaman-pengalaman yang memberikan gambaran kehidupan pribadi seseorang. Cerita ini akan direkam untuk nantinya diulas kembali dan dianalisis sebagai data deskriptif mengenai persepsi, reaksi, dan berbagai macam hal yang berpengaruh dalam mengubah perilaku seseorang tersebut. Banyak peneliti dan penulis etnografi yang menggali dan mendeskripsikan cerita hidup seseorang sebagai bagian penting dalam penelitian mengenai strategi (cara pengelolaan).

\section{PEMBAHASAN}

Counihan (2004:24) mengemukakan terminologi "eating is recalling" karena kemampuan makanan atau minuman itu membawa manusia menemukan makna dan ingatan tentang sesuatu hal. Tidak hanya makanan atau minuman, cita rasa menurut Montanari (2006: 61) juga merupakan produk budaya. Kriteria mengenai apa yang disukai dan tidak disukai bervariasi tergantung waktu dan tempat. Disukai atau tidak disukai adalah apa yang dipahami sebagai selera. Sesuatu yang dimakan, dilihat, dan dibaca telah dikonstruksi dalam ruang sejarah yang konkrit secara sosial, sehingga tidak mungkin tanpa kepentingan (rasionalitas 
selera murni). Mintz (2008:21) dalam pemahaman yang lebih mendalam menyatakan bahwa dalam masyarakat, aktivitas makan sebuah makanan mempunyai nilai simbolik tersendiri. Makanan dikonsumsi setiap hari, terbentuk dengan kontekstual yang kuat sehingga dapat menentukan perbedaan identitas seseorang.

Saat kopi diperjual-belikan, kegiatan minum kopi memiliki persoalan baru, yaitu ada selera yang harusnya ditularkan sehingga dibeli oleh konsumen. Kopi yang menjadi kesukaan penjualnya, juga harus memiliki kekhasan dihadapan konsumen agar menjadi pilihan konsumen diantara kedai-kedai kopi yang lain,

"Harus diakui, kopi ala Jawa Timuran kayak Grisse, Blandongan dan Semesta itu banyak mempengaruhi selera rasa kopiku sekarang, karena memang sampai sekarang aku lebih suka kopi yang bodinya tebal dan rasa kopi yang tajam. Pun ketika aku bekerja jadi menajer di Legend Coffee, sebelum opening kan aku sempet belajar espresso based dulu, karena Legend Coffee waktu itu akan memakai mesin espresso. Waktu itu aku belajarnya di Bali sama temen yang memang udah berpengalaman. Disana aku dikasih espresso dan semua minuman turunannya yang pake susu dengan rasa yang gurih, dominan kacang-kacangan, dan bodinya juga tebal. Akhirnya karakter rasa seperti itulah yang aku bawa dan hadirkan di Legend Coffee dan kedai-kedai kopi lain sampai ke Magistra Coffee sekarang". (Ferry, 12 Februari 2019)

Pengalaman informan tersebut dalam meminum kopi dan bekerja di kedai kopi yang berlangsung lama itu telah menjadi kebiasaan yang menubuh sehingga menentukan dasar dari selera rasanya. Saat Ferry dihadapkan tantangan untuk mempelajari soal produk minuman baru, yaitu berbahan dasar espresso (espresso based), keputusannya untuk memilih belajar di Bali dengan dengan temannya itu, jelas tidak bisa dilepaskan dari peran dasar seleranya yang telah menubuh itu, sehingga secara kognitif mengarahkannya kepada temannya yang menyodorkan karakter rasa relatif sama meskipun produk kopinya berbeda.

Berawal dari Legend Coffee itulah Ferry mulai menghadirkan produk kopi berdasarkan ingatannya. Rasa dari kopi yang dia hadirkan merupakan bentuk perwujudannya atas ingatan-ingatan tentang kebiasaannya dulu. Ada perbedaan kondisi yang terjadi pada Ferry antara di tempat yang membentuk seleranya dan yang di kedai-kedai kopi yang ditularkan seleranya. Perbedaan pertama 
sebenarnya bersumber dari jabatan yang dipegangnya, yaitu sebagai barista dan manajer. Saat menjadi barista, dia adalah orang yang diajarkan, menerima berbagai informasi yang pada akhirnya membentuk seleranya atas rasa kopi. Saat menjadi manajer, baik itu manajer produk, pemasaran dan operasional dia menjadi orang yang telah memiliki kekuasaan untuk mengajarkan dan mengarahkan orangorang yang bekerja di bawah kontrolnya, yaitu para barista untuk setuju dan menjual produk kopi sesuai selera rasanya.

Bagaimana dengan Magistra Coffee? Seperti apa proses transfer selera yang terjadi pada kedai kopi yang dimilikinya itu dengan adanya keterlibatan Samhan (informan) sebagai barista yang dipandangnya memiliki pengetahuan yang cukup mumpuni. Ada perbedaan proses dan hasil akhir dalam transfer selera Ferry di kedai kopinya sendiri. Dilibatkannya Samhan menghadirkan kompleksitas dan kompromi-kompromi yang sebelumnya (di kedai-kedai dahulu) tidak terjadi,

"Setiap Samhan datang ke Magistra dulu, aku inget dia selalu membanggakan hasil seduhannya yang pakai vietnam drip. Ketika aku cicipi, ternyata rasanya mirip dengan seleraku. Tapi menurutku, dia waktu itu belum benar-benar menentukan selera rasanya. Sedikit banyak memang ada pengaruhku dalam membentuk selera Samhan, karena dia kan belajar espresso based nya sama aku, sambil kerja di Magistra dengan bahan baku yang aku pilih, yang dapat menghasilkan rasa sesuai seleraku". (Ferry, 20 Februari 2019)

"Kalo soal selera kopi, dulu itu kan kalo sama kopi, aku istilahnya lebih ke mengeksplore Bay... Makanya sampe mau kerja di Magistra karena mau belajar espresso based lagi kan. Jadi kalo ditanya soal seleraku kayak gimana, menurutku semuanya enak sih. Nggak berpatokan sama rasa tertentu terus. Kalo soal rasa seduhan kopi, ada cerita unik ini. Jadi pernah dulu di Top Gear Coffee, iseng-iseng aku sama mas Ferry ikut battle v60, kami nyeduh bareng dua temen lainnya pake kopi yang sama tuh. Pas hasil seduhannya dicicipin sama temen-temen yang jadi juri, mereka bilang ada dua kopi yang rasanya sama, pasti berdua ini perguruannya sama. Aku sama Ferry dan teman-teman yang lain langsung tertawa. Padahal tidak janjian itu, mau pakai teknik gimana nyeduhnya.... "(Samhan, 23 Februari 2019)

Dari pernyatan Ferry dan Samhan di atas, ada dua hal penting yang memiliki keterkaitan terhadap keputusan karakter rasa yang akan dijual di Magistra Coffee, yaitu kemampuan Ferry mempengaruhi Samhan dan kekayaan 
pengalaman rasa yang dimiliki Samhan. Bagi Samhan, kenikmatan minum kopi itu berasal dari prosesnya mencari tahu bagaimana rasa kopi itu dapat bermacammacam, meskipun secara tampilan warnanya sama. Proses mengetahui ini menjadi kenikmatan tersendiri bagi Samhan karena diketahuinya secara bertahap dan pengetahuan tersebut saling terkait dalam menghasilkan perbedaan rasa dan aroma dari kopi. Saling bergantungnya variabel-variabel pengetahuan yang membentuk rasa kopi, melahirkan candu bagi Samhan untuk terus menguliknya. Hal tersebut, sejalan dengan yang dikatakan Telfer (2012: 38) mengenai minum (drink) dan sekadar aktivitas memberi air (watering) untuk mempertahankan hidup.

Keputusan mengikuti tren eksplorasi rasa kopi ini dipandang Ferry sebagai suatu strategi untuk memperkenalkan kedai kopi mereka kepada segmen pasar yang dituju. Menjadikan hal tersebut sebagai startegi dinilai relevan mengingat pada saat itu Magistra Coffee baru enam bulan lebih berdiri, dan sedang ada fenomena umum yang saat itu terjadi di perkopian Yogya, yaitu eksplorasi rasa kopi, khususnya kopi manual brewing. Menurut pengakuan Ferry, strategi itu berhasil menarik perhatian mahasiswa, serta beberapa karyawan dan dosen yang memang sedang menggandrungi kopi manual brewing, hasil penjualan untuk kopi jenis ini yang biasanya berkisar lima sampai sepuluh gelas per hari, menjadi lima belas gelas per hari. Menjelang dua tahun mengikuti tren ini, Ferry dan Samhan mulai melakukan evaluasi operasional, dalam arti mereka melakukan pemetaan para konsumen yang rutin datang dan jenis kopi yang laris dipesan. Berdasarkan data yang diperoleh ini, mereka mulai menemukan segmen pasarnya dan fokus merawat para pelanggan yang setia ini dengan menghadirkan jenis kopi dan karakter rasa yang secara umum disenangi.

Tindak lanjut dari pemetaan yang sudah dilakukan adalah kalibrasi, istilah kalibrasi dalam dunia kopi mengacu pada penentuan pengaturan tertentu dalam rangka menghasilkan rasa kopi tertentu sesuai dengan yang diinginkan. Setiap perbedaan perpaduan pengaturan yang ditetapkan terkait jumlah kopi yang digunakan, suhu air, rasio dan waktu seduh akan menghasilkan rasa yang berbeda. Proses kalibrasi di Magistra Coffee dilakukan untuk dua tujuan, pertama sesuai dengan tujuan dari kalibrasi itu sendiri, yaitu menghasilkan karakter rasa yang 
diinginkan untuk menjadi ciri khas mereka. Kedua, untuk terus menghasilkan pengaturan yang tepat agar karakter rasa kopi yang dihasilkan setiap harinya konsisten. Kalibrasi menjadi penting untuk menjaga konsistensi rasa karena kualitas biji kopi mengalami perubahan dari hari ke hari, sehingga seringkali resep yang sudah ditetapkan diawal tidak lagi menghasilkan rasa yang diinginkan. Di Magistra Coffee, hanya Ferry dan Samhan yang memiliki wewenang melakukan kalibrasi dengan tujuan untuk memastikan suatu resep tetap digunakan atau direvisi setiap harinya.

\section{Budaya Perusahaan, Identitas dan Reputasi}

Semenjak suatu usaha dirintis oleh satu orang atau lebih hingga kemudian berkembang menjadi perusahaan yang memberikan suatu kebanggaan tidak hanya kepada pemiliknya tetapi juga kepada para pelanggannya yang setiap hari datang untuk membeli produknya, pada hakekatnya telah terbentuk suatu identitas organisasi perusahaan tersebut. Faktor penentu kesuksesan perusahaan terletak pada peranan penting identitas organisasi sebagai pembeda (Altiok, 2011; Javadi \& Yavarian, 2011).

Srawung dalam bahasa Jawa adalah terminologi yang sering diartikan sebagai pertemuan atau kegiatan berkumpul yang melibatkan lebih dari satu orang (kelompok). Dikatakan Christian (2018: 1-2) srawung sendiri mengandung filosofi yang cukup mendalam, melekat secara khas sebagai bagian dari tatanan nilai masyarakat Jawa dikarenakan bukan hanya adanya perjumpaan, melainkan juga adanya pembelajaran bersama antar individu melalui penyampaian realitas yang terjadi disekitar masing-masing baik yang ada di dalam pikiran maupun perasaan, serta menimba inspirasi (ngangsu krawuh).

Budaya srawung dapat terwujud dari berbagai bentuk, salah satunya dalam aktivitas berkumpul minum kopi bersama seperti yang ada di Magistra Coffee. Srawung yang menjadi budaya perusahaan di Magistra Coffee dimulai dari kebiasaan serupa yang telah terlebih dahulu diterapkan kedua pemiliknya. Srawung sendiri berarti bergaul, Ferry dan Rasti sejak dulu memiliki hobi nongkrong minum kopi, memperluas pergaulannya dalam hobi yang sama. Srawung di kedai kopi pada prakteknya sebenarnya tidak sulit dilakukan 
mengingat kegiatan nongkrong di kedai kopi merupakan suatu aktivitas yang dilakukan seseorang untuk mengisi waktu luangnya.

Motto Magistra Coffee, yaitu "Our Coffee Taste Better Than Your Lips" telah menyiratkan makna bahwa adanya hubungan dan percakapan yang intens antara individu-individu di dalam Magistra Coffee dengan para pelanggannya. Hal tersebut senada dengan penelitian yang dilakukan Davis (1995) tentang makanan di Minangkabau, ia mengatakan bahwa bagi orang Minangkabau makanan merupakan sesuatu yang memiliki makna ekspresi yang penting dalam komunikasi antar kelompok seperti kepercayaan, keselarasan, konflik, kecurigaan, status, dan simbol terciptanya hubungan baru yang berkelanjutan. Di Magistra Coffee, adanya hubungan sosial yang intim ini memberikan pengalaman ngopi yang khas bagi para konsumen, sehingga mereka bersedia kembali lagi dan menjadi pelanggan tetap yang setiap hari datang.

Magistra Coffee memberikan kenikmatan kepada pelanggan tidak hanya dari sensasi citarasa kopi yang mereka jual, melainkan juga dari pelayanan mereka. Yaitu pelayanan dalam soal memberikan informasi seputar kopi mulai dari hulu (kebun) sampai ke hilir (penyeduhan). Adanya pelayanan ini pun sejalan dengan arti nama Magistra yang dikatakan Ferry yaitu, Guru. Sebagaimana seorang guru, Ferry dan Samhan selalu bersedia menjawab berbagai pertanyaan seputar kopi yang ditanyakan para pelanggannya. Mereka membuka ruang diskusi saat para pelanggannya memang sedang memiliki waktu untuk meminum kopinya lebih lama. Mengenai ada tidaknya waktu yang dimiliki pelanggan ini diketahui mereka dengan memperhatikan perilaku mereka saat berada di Magistra Coffee. Pelanggan yang sedang sibuk biasanya akan meminum kopi sambil membuka laptop atau mengeluarkan kertas kerjanya atau mereka akan memilih untuk membawa pergi (take away) pesanannya.

Kebersediaan Ferry dan Samhan meluangkan waktu untuk menjalin komunikasi dengan para pelanggannya, di sisi lain tidak lagi hanya dipandang sebagai suatu kegemaran pribadi mereka masing-masing. Interaksi yang mereka bangun kepada pelanggan adalah upaya mereka untuk membangun hubungan demi keberlangsungan Magistra Coffee. Hubungan yang diinginkan mereka tidak hanya 
bersifat transaksional yaitu sebatas penjual dan pembeli, namun menggunakan analogi pertemanan. Proses itu diawali dengan perkenalan, yaitu saat para pelanggan ini pertama kali datang ke Magistra, berlanjut dengan mulai menjalin interaksi setelah kedatangan kedua dan seterusnya.

Selain untuk mengikat konsumen, srawung juga bertujuan untuk memetakan kebutuhan dan keinginan para pelanggannya. Pemetaan ini menjadi penting karena para target konsumen mereka didominasi orang-orang yang sama sepanjang satu tahun, mengikuti waktu penerimaan mahasiswa/i baru. Srawung kepada pelanggan selain untuk kepentingan produk yang mereka jual agar dapat diterima, juga digunakan untuk merekrut karyawan. Semua karyawan yang bekerja di Magistra adalah para pelanggan loyal Magistra Coffee dan orang-orang yang sudah saling kenal dekat dengan kedua pemilik Magistra. Ketertarikan dan kecocokan dengan karyawan yang dipetakannya saat srawung menjadi dua hal yang penting karena akan berhubungan dengan kepuasan kerja karyawan dan kepuasan pelanggan. Kepuasan kerja menjadi elemen penting karena dapat mempengaruhi perilaku kerja dari karyawan seperti efektifitas dan produktifitas kerja. Kepuasan kerja didefinisikan Kreitner dan Kinicki (2005: 224) sebagai gambaran reaksi emosional yang diberikan oleh seseorang saat melaksanakan pekerjaannya. Sedangkan kepuasan pelanggan, merupakan merupakan tujuan dari pengembangan budaya perusahaan yang didefinisikan sebagai strategi untuk menarik klien dan konsumen sebanyak mungkin dan tetap setia (Kalangie, 1997:9). Seorang pelaku bisnis dalam dunia retail bernama Neiman-Marcus mengingatkan kepada seluruh karyawannya, "sell satisfaction not just merchandise" (dalam Irawan, 2002:1). Pada akhirnya dua bentuk kepuasan tersebut akan menentukan performa kedai kopi mereka agar mampu bertahan lama.

Puncak dari keintiman relasi ini adalah perhatian kepada pelanggan seperti kepada teman sendiri, yaitu menghadirkan citarasa kopi sesuai dengan yang dibutuhkan mereka. Magistra Coffee berupa semaksimal mungkin untuk mengerti para pelanggannya sedekat mungkin. Dengan cara menyapa para pelanggan yang sedang ingin memesan kopi dengan menyebutkan nama mereka dan menghafal 
pesanan yang biasa yang dipesan. Bagi para pelanggan yang setiap hari datang pun mereka tidak perlu lagi menyebutkan pesanan mereka, karena para barista sudah sangat mengerti apa yang pelanggannya butuhkan.

Kelanggengan usaha yang menjadi tujuan utama Ferry, membuatnya tidak berfokus pada tingginya angka penjualan namun pada kepastian angka penjualan. Kepastian angka penjualan Magistra Coffee ini bersumber dari loyalitas para konsumen yang sudah menjadi teman, sehingga penting untuk memastikan porsi terbesar pembeli kopi mereka adalah para teman (pelanggan loyal) ini. Cara yang dilakukan adalah dengan terus menciptakan teman-teman baru dari konsumen yang dianggap mereka berpotensi. Konsumen potensial ini datang dari konsumen yang sudah menjadi teman sebelumnya melalui proses rekomendasi.

Penerapan budaya srawung sebagai dasar dari cara Magistra Coffee menjual produk dan melayani pelanggan sehari-hari tersebut melahirkan identitas bagi kedai kopi mereka yaitu dikenal sebagai coffee consultant. Identitas ini bukanlah sesuatu yang direncanakan dari awal berdirinya kedai kopi ini, mengikuti logika yang dikemukakan oleh Boudon (2016:5) tentang adanya perverse effect dalam suatu action, terbentuknya identitas bukan sebagai sesuatu yang diniatkan dari awal oleh pelaku, melainkan akibat yang muncul kemudian. Akibat yang muncul (dalam hal ini yakni identitas perusahaan) ini kemudian dimaknai secara positif oleh pihak manajemen dan terus dikonsistenkan. Terjadinya proses pembentukan identitas perusahaan pada Magistra Coffee menunjukkan apa yang dikatakan Woodward (2004: 2) bahwa identitas “...is most clearly defined by difference...". Whyte (2009: 7) juga menyatakan bahwa “identity is about similarity and difference between selves and others." Keterlibatan the other atau 'sesuatu yang lain' sangat penting dalam proses pembentukan identitas. Interaksi pengaruh lingkungan (eksternal) dan pribadi (internal) dapat membentuk suatu identitas (invididu dan kelompok), maka dari itu identitas bersifat kontekstual. Perasaan, motivasi, nilai, dan keyakinan merupakan pengaruh internal yang mampu mempengaruhi terbentuknya identitas (Giles dan Middleton, 1999: 34).

Mengenai identitas Magistra Coffee sebagai "Coffee Consultant" ini juga sejalan dengan yang definisi identitas organisasi sebagai bagian penting 
perusahaan yang didefinisikan oleh Oliver, Statler, \& Roos, (2010) sebagai sebuah tanda yang inheren atau ciri khas perusahaan, sehingga bukan semata-mata dicerminkan oleh merek atau format simbol perusahaan. Identitas perusahaan secara lebih luas juga meliputi peraturan, adab kerja dan atribut spesifik yang merekat di perusahaan (Marin, Ruiz \& Rubio, 2009). Istilah coffee consultant ini penulis hadirkan pada dasarnya karena adanya kecenderungan Ferry dan Samhan yang sangat memahami produk serta bisnis kopi dan senang berbincang dengan para pelanggan. Ketika mereka melayani pelanggan yang memiliki ketertarikan sama dengan dirinya maka biasanya mereka akan berbincang-bincang lama dan membangun keakraban dalam pembicaraan mereka. Perilaku "konsultasi kopi" ini mulai menguat sejak bergabungnya Samhan di Magistra Coffee, yaitu saat kedai kopi ini baru berjalan sekitar enam bulan. Pada saat itu fenomena kedai kopi yang fokus terhadap pengenalan pengetahuan pengelolaan kopi dan penyajian kopi (kedai kopi gelombang ketiga) baru mulai ramai bermunculan. Antusiasme para pengunjung kedai kopi untuk ikut mencari tahu soal kopi juga mulai tinggi. Samhan sebagai satu-satunya barista yang direkrut dengan telah terlebih dahulu memiliki pengalaman dan pengetahuan, ikut terbawa antusiasme para pelanggan yang datang memesan kopi dengan penuh rasa penasaran. Dia senang meladeni para pelanggan yang setiap setelah selesai bertransaksi tetap berada di depan bar memperhatikan dia membuat kopi sambil mengajukan banyak pertanyaan seputar kopi.

Samhan yang saat itu memiliki pengetahuan lebih banyak dari barista lainnya, ternyata tetap masih memiliki keterbatasan dalam menjelaskan kepada para pelanggan karena pada awalnya tujuan bekerja di Magistra adalah untuk belajar lebih lanjut dengan Ferry. Ferry yang melihat adanya keterbatasan jawaban yang diberikan Samhan saat melayani pelanggan, memaksa dirinya untuk ikut terlibat dalam perbincangan dengan para pelanggan yang masih awam terhadap kopi. Pada dasarnya, Ferry adalah orang yang juga senang berbincang soal kopi, namun dia cenderung lebih selektif dalam memilih lawan bicara, berbeda dengan Samhan. Awalnya Ferry lebih senang berbincang dengan sesama penggiat kopi yang level pengetahuannya relatif sama agar tidak terjadi pengulangan bahasan. 
Namun, apa yang dilihatnya pada Samhan, menyadarkannya bahwa di kedai kopinya semakin banyak penikmat kopi yang awalnya hanya suka minum kopi saja menjadi tertarik untuk mendalami pengetahuan soal kopi juga.

Muncul keyakinan di diri Ferry bahwa dengan ikut mengedukasi atau membagikan pengetahuan soal kopi kepada para pelanggan berarti juga secara khusus sebagai upaya untuk mereproduksi atau memperbanyak jumlah pelanggannya dan penikmat kopi pada umumnya. Semakin banyak pengetahuan yang didapatkan pelanggan, baik dari segi teknis maupun teori, akan ikut meningkatkan konsumsi kopinya. Ciri khas coffee consultant terletak pada tidak terbatasnya pengetahuan yang dibagikan, penekanan mereka adalah pada teredukasinya para pelanggan. Mereka tidak segan merekomendasikan varian kopi atau kedai kopi lain yang memang sesuai keinginan pelanggan, tidak melulu mengarahkannya pada produk yang ada Magistra Coffee. Namun meski demikian, mereka juga tetap memberikan relevansi akan produk yang Magistra jual dengan pernyataan-pernyataan yang luput dipikirkan para pelanggan. Pernyatan tersebut biasanya mengenai keefektifan produk yang didapatkan dan uang yang dikeluarkan. Dengan membeli produk kopi Magistra yang terkenal bold dan strong, dalam sehari mereka tidak perlu mengonsumsi dan membeli banyak kopi jika dibandingkan dengan karakter kopi yang light dan fruity. Dari sisi harga, mereka juga kembali mengingatkan pelanggannya tentang tujuan mereka datang ke kedai kopi. Jika tujuannya hanya untuk memenuhi kebutuhan kafein, Magistra adalah pilihan yang tepat karena harga yang mereka berikan lebih murah. Murahnya harga kopi di Magistra selain karena kepiawaian Ferry mencari pemasok bahan baku, juga karena tidak adanya biaya fasilitas seperti wifi, $A C$ dan fasilitas pendukung lainnya yang dimasukkan ke dalam harga produk.

Reputasi yang positif dapat memberikan kontribusi terhadap suksesnya suatu perusahaan. Crumlish (2004: 69-70) mengatakan bahwa orang-orang ingin membangun reputasi atau status, dengan cara ikut terlibat dalam diskusi kelompok yang ada, di komunitas virtual yang dikutinya, mengelola blog yang dimiliki untuk mempromosikan keahliannya, dan memamerkan hasil karyanya atau menunjukkan kepintarannya. Magistra Coffee ingin menyampaikan esensi dari bisnis kedai kopi 
itu sendiri kepada setiap pelanggannya dengan baik, sehingga pihak manajemen membutuhkan sosok yang sangat paham pengetahuan soal kopi dan bisnis kedai kopi itu sendiri. Bertindak sebagai coffee consultant merupakan suatu strategi utama Magistra yang ditujukan untuk menarik perhatian setiap pelanggan dan tentunya untuk membuat kedai kopi tersebut lebih unggul dengan memiliki kredibilitas dan reputasi yang baik dibandingkan dengan kedai kopi yang lain. Sebagaimana studi Dowling (2000) yang memperlihatkan jika perusahaan mempunyai image dan reputasi yang baik maka hal tersebut dapat selalu digunakan untuk mendukung aktivitas bisnis perusahaan. Namun jika perusahaan memiliki reputasi yang buruk maka hal itu harus dibayar mahal untuk memperbaikinya.

Adanya perilaku "konsultasi kopi" di Magistra ini, selain sebagai satu perwujudan dari budaya srawung mereka, juga sekaligus dapat digunakan untuk terus menjaga reputasi mereka, sebagaimana yang dikatakan oleh Panchanathan (2010: 7), bahwa reputasi akan tersiar secara luas melalui gosip dan pembicaraan kelompok di dalam masyarakat, yang mana pola ini sudah berlangsung lama di dalam masyarakat selama manusia berevolusi. Pada akhirnya, kebiasaan srawung yang diterapkan dan seringnya kopi menjadi tema obrolan membuat kapasitas dan kredibilitas Magistra Coffee ikut terangkat dan sering dijadikan rujukan untuk berkonsultasi mengenai bisnis kopi. Diakuinya reputasi Magistra Coffee yang diwakili oleh Ferry dan Samhan dibuktikan dengan seringnya mereka diundang sebagai pembicara di acara-acara bertema kopi di Yogyakarta.

\section{KESIMPULAN}

Mengulas kopi dalam konteks budaya tentu akan merujuk pada persoalan praktis serta perilaku konkretnya dalam masyarakat. Pada artikel ini, salah satu perilaku berkenaan dengan kopi yang diteliti adalah aktivitas jual-beli kopi dalam bentuk kedai kopi, yaitu Magistra Coffee. Berawal dari dimaknai kopi sebagai minuman sosial, yaitu menjadi media untuk berkumpul bersama-sama. Seringkali perilaku lain yang berkorelasi dengan kopi sebenarnya lebih penting daripada perilaku meminum kopi itu sendiri.

Fokus penelitian di artikel ini, yaitu persoalan pengelolaan kedai kopi yang 
dilakukan pihak manajemen memiliki dinamika dan kekhasannya sendiri, seperti juga yang terjadi pada penelitian dengan konsumen sebagai informannya. Budaya perusahaan menjadi konsep yang relevan untuk digunakan selanjutnya, karena srawung sebagai budaya perusahaan yang ada di Magistra Coffee sangat menitikberatkan pada "pertemuan" (aktivitas sosial yang berlangsung) daripada produk kopinya sendiri. Pengelolaan kedai kopi dengan menerapkan budaya perusahaan (srawung) yang konsisten kemudian melahirkan elemen penting dalam menjaga keberlangsungan kedai kopi, yaitu identitas perusahaan.

Identitas perusahaan yang lahir dengan mekanisme seperti ini, yaitu dari pandangan pelanggan membuat pihak manajemen memperlakukan identitas tersebut dengan penuh semangat, karena identitas yang disematkan ini dimaknai sebagai penilaian positif atas pelayanan mereka. Identitas sebagai coffee consultant merupakan pemaknaan dari pelanggan atas cara pihak manajemen menjual produknya dan melayani para pelanggannya. Dengan situasi yang demikian, dalam rangka mempertahankan identitas yang telah tersematkan itu, pihak manajemen Magistra Coffee tidak memerlukan strategi tertentu, penerapan budaya perusahaan (srawung) mereka sekaligus bermanfaat dalam merawat identitas sebagai coffee consultant itu.

Keunikan srawung sebagai suatu budaya perusahaan semakin terlihat ketika budaya ini juga mampu memberikan manfaat terhadap identitas mereka, yaitu memberikan reputasi atas identitas itu. Di tengah persaingan bisnis kedai kopi kecil yang semakin ketat, agar dapat berumur panjang reputasi atas identitas kedai kopi menjadi sangat krusial. Reputasi dalam bisnis kedai kopi biasanya berkorelasi dengan nama baik dan pengakuan eksistensi yang diperoleh dari kepemilikan tingkat pengetahuan dan penguasaan pihak manajemen terhadap produk kopi dan keberhasilannya merawat pelanggan. Hal itu dikarenakan tipikal bisnis kedai kopi yang terus mengalami perkembangan dalam hal pengetahuan dan penyajian kopi serta tren peminum kopi.

Akhirnya, memandang bisnis kedai kopi dalam konteks budaya dengan terlebih dahulu menempatkan kopi (minuman) sebagai produk budaya mengarahkan penelitian ini untuk menganalisis budaya perusahaan yang berlaku di 
kedai kopi tersebut. Selanjutnya, melalui budaya perusahaan akan terungkap identitas yang disematkan maupun tersematkan pada suatu kedai kopi. Identitas ini kemudian akan menemukan signifikansinya dalam menjaga keberlangsungan kedai kopi jika memiliki reputasi yang baik dan terus dipertahankan.

\section{DAFTAR PUSTAKA}

Anderson, F., 1986. Antropologi Kesehatan. Jakarta: Penerbit Universitas Indonesia.

Berg, C., 2008. Memo Starbucks: Next Time Try Selling Ice to Eskimos. The Sunday Age, 3.

Biderman, B., 2013. A People's History of Coffee and Cafes. Black Apollo Press.

Boudon, R., 2016. The Unintended Consequences of Social Action. Springer.

Counihan, C., 2004. Around the Tuscan Table: Food, Family, and Gender in Ttwentieth-century Florence. Psychology Press.

Cowan, B., 2008. The Social Life of Coffee: The Emergence of the British Coffeehouse. Yale University Press.

Crumlish, C., 2004. The Power of Many: How the Living Web is Transforming Politics. Business, and Everyday Life, Sybex, San Francisco, CA.

Davis, C., 1995. Hierarchy or Complementarity? Gendered Expressions of Minangkabau Adat. Indonesia Circle, 23(67), pp.273-292.

De Koning, A., 2006. Café Latte and Caesar Salad: Cosmopolitan Belonging in Cairo's Coffee Shops. In Cairo Cosmopolitan: Politics, Culture, and Urban Space in the New Globalized Middle East. Diane Singennan and Paul Amar, eds. Pp. 221-233. American University in Cairo Press.

Dowling, G., 2000. Creating Corporate Reputations: Identity, Image and Performance. OUP Oxford.

Ellis, M., 2011. The Coffee-House: A Cultural History. Weidenfeld \& Nicolson.

Giles, J. and Middleton. 1999. Studying Culture-A Practical Introduction, Malden, MA: Blackwell Publishers.

Fetterman, D.M. 1989. Ethnography Step by Step. Applied Social Research Methods, (17). New Delhi: Sage Publications. 
Irawan, H., 2002. Sepuluh Prinsip Kepuasan Pelanggan. Jakarta. Penerbit Elex Media Komputindo Kelompok Gramedia.

Kalangie, Nico, 1997. Pendekatan Kebudayaan Korporat Dalam Pengembangan Organisasi. Jurnal Ilmu Sosial dan Humaniora, 2 (3). Universitas Sam Ratulangi.

Kian, A.M.L., 2018. Kumpulan Essay: Srawung Menuju Peradaban Kasih. SCU Knowledge Media.

Kottak, C. P. 2011. Cultural Anthropology, Fourteenth Edition. Singapura: McGraw-Hill.

Kreitner, R. and Kinicki, A., 2005. Perilaku Organisasi. Jakarta: Salemba Empat.

Laurier, E., Whyte, A. and Buckner, K., 2001. An ethnography of A Neighbourhood Café: Informality, Table Arrangements and Background Noise. Journal of Mundane Behaviour, 2(2), pp.195-232.

Lincoln, Y.S. and Denzin, N.K. eds., 1994. Handbook of Qualitative Research. Sage Publication.

Manning, P., 2008. Barista Rants About Stupid Customers at Starbucks: What Imaginary Conversations Can Teach Us About Real Ones. Language \& Communication, 28(2), pp.101-126.

Manzo, J., 2010. Coffee, Connoisseurship, and An Ethnomethodologicallyinformed Sociology of Taste. Human Studies, 33(2-3), pp.141-155.

Manzo, J., 2014. Machines, People, and Social Interaction in "Third-Wave" Coffeehouses. Journal of Arts and Humanities, 3(8), pp.1-12.

Manzo, J., 2015. "Third-Wave" Coffeehouses as Venues for Sociality: On Encounters Between Employees and Customers. The Qualitative Report, 20(6), p.746.

Marin, L., Ruiz, S. and Rubio, A., 2009. The Role of Identity Salience in The Effects of Corporate Social Responsibility on Consumer Behavior. Journal of business ethics, 84(1), pp.65-78.

Milligan, M. J., 1998. Interactional Past and Potential: The Social Construction of Place Attachment. Symbolic Interaction, 21(1), 1-33.

Mintz, S.W., 2008. Food, Culture and Energy dalam Frank Treanmant dan Alexander Nutzenadel (ed.) Food Globalization. New York: Berg.

Montanari, M., 2006. Food is Culture. Columbia University Press. 
Oliver, D., Statler, M. and Roos, J., 2010. A Meta-ethical Perspective on Organizational Identity. Journal of Business Ethics, 94(3), pp.427-440.

Panchanathan, K., 2010. Reputation and The Evolution of Social Behavior. University of California, Los Angeles.

Papachristos, A.V., Smith, C.M., Scherer, M.L. and Fugiero, M.A., 2011. More coffee, Less Crime? The Relationship Between Gentrification and Neighborhood Crime Rates in Chicago, 1991 to 2005. City \& Community, 10 (3), pp.215-240.

Pendergrast, M., 2010. Uncommon Grounds: The History Of Coffee and How It Transformed Our World. Basic Books.

Reitz, J.K., 2007. Espresso: A Shot of Masculinity. Food, Culture \& Society, 10(1), pp.7-21.

Stamberg, Susan, 2002. The Coffee Break. NPR.

http://ipad.npr.orglprograms/morning/features/patc/coffee break/index.html

Telfer, E., 2012. Food for Thought: Philosophy and Food. Routledge.

Thompson, C.J. and Arsel, Z., 2004. The Starbucks Brandscape and Consumers (anticorporate) Experiences of Glocalization. Journal of consumer research, 31(3), pp.631-642.

Tucker, C.M., 2011. Coffee Culture: Local Experiences, Global Connections. Routledge

Turner, C., 1992. Creating Corporate Culture: From Discord to Harmony.

Waxman, L., 2006. The Coffee Shop: Social and Physical Factors Influencing Place Attachment. Journal of Interior Design, 31(3), pp.35-53.

Weber, F., 2001. Settings, Interactions and Things: A Plea for Multi-integrative Ethnography. Ethnography, 2(4), pp.475-499.

Whyte, S.R. 2009. "Health Identities and Subjectivities: The Ethnographic Challenge," Medical Anthropology Quarterly, 23(1): 6-15.

Woodward, K. ed., 2004. Questioning Identity: Gender, Class, Nation. Routledge. 